\title{
Relationship between attributes of individual workers and concentration at work
}

\author{
Reo Sugino ${ }^{1, *}$, Shin-ichi Tanabe ${ }^{1}$, Mikio Takahashi ${ }^{2}$, Tomoko Tokumura ${ }^{2}$, Kazuki Wada ${ }^{2}$, Tomohiro Kuroki ${ }^{2}$, \\ Jun Nakagawa ${ }^{1}$, Jun Shinoda ${ }^{1}$, and Takuma Shinoyama ${ }^{1}$
}

${ }^{1}$ Waseda University, 3-4-1 Okubo, Shinjuku-ku, Tokyo 169-8555, Japan

${ }^{2}$ Takenaka Corporation, 5-1-1 Otsuka, Inzai-shi, Chiba 270-1395, Japan

\begin{abstract}
Working environments are becoming far more diverse. For example, Activity-Based Working (ABW), a new style of working where workers choose their own work environment, is now attracting attention. An office that introduces ABW is comprised of various spaces, including open plan workspaces, corresponding to the ways of working. However, such an office may result in distraction. Therefore, it is necessary to identify the environmental factors that affect individual workers' concentration at work. This study aimed to ascertain the relationship between individual workers' attributes, such as the Big Five personality traits, personal control, and age, and the factors that distract them from their work. A questionnaire-based field survey was conducted at an office that partially adopted $\mathrm{ABW}$ to investigate the relationship between selection of seats and concentration at work. The results revealed different tendencies among workers for the type of work environment needed to concentrate according to their individual attributes. Additionally, it was suggested that the changing of seats lead to improved concentration at work, thus increasing productivity.
\end{abstract}

\section{Introduction}

In Japan, the number of workers is expected to decline due to rapid population declines, decreasing birth rates, and an aging population. Therefore, it is a social challenge to maintain the mental and physical health of workers, to motivate them, and to improve their intellectual productivity in order to achieve sustainable economic growth. Further, with the advancement of information technology, working environments are becoming far more diverse.

For example, Activity-Based Working (ABW), a new style in which workers choose their own work environment, is now attracting attention. An office that introduces $\mathrm{ABW}$ comprises various spaces, including open plan workspaces, each corresponding to the ways of working. However, previous field studies have revealed that the provided space was not necessarily used as intended, and it has been suggested that simply introducing $\mathrm{ABW}$ does not contribute to improving intellectual productivity [1]. Specifically, although such an office may activate communication, it may cause distraction due to conversation and noise or the lack of privacy [2]. Thus, it is necessary to pay close attention to the work style of each worker and to clarify the environmental factors which are important for concentration at work.

Previous studies focusing on individual workers in terms of personality, occupation, and age have revealed the possibility that individual workers' attributes may affect their perception of the office environment, such as the environmental satisfaction level, environment preference, etc. [3, 4]. However, few studies have examined both the attributes and environmental factors in detail.

The present study aimed to ascertain the relationship between individual workers' attributes, including the Big Five personality traits, personal control, and age, and the factors that distract them from their work.

\section{Methods}

\subsection{Outline of the surveyed offices}

A questionnaire-based survey was conducted in a technical research institute located in Chiba Prefecture, Japan. Additionally, a field survey using a more detailed questionnaire was conducted in a laboratory in which ABW was partially adopted.

Fig. 1 shows the layout of the observed ABW office. The target ABW office belongs to a department with 2 divisions and 5 groups, and $\mathrm{ABW}$ was introduced in April 2016, with the installation of 20 assigned and 54 unassigned seats. When installing $\mathrm{ABW}$, assigned-seat workers were given reduced personal space. About $80 \%$ of the workers who did not have assigned seats in the ABW office worked on laptop personal computers (PCs)

* Corresponding author: sugino@tanabe.arch.waseda.ac.jp 
and were able to select their office locations based on their work content and preferences. The unassigned seats included concentration spaces (with a front and side dividers), semi-concentration spaces (with a front divider), open spaces (with no dividers), movable table spaces, and communication spaces.

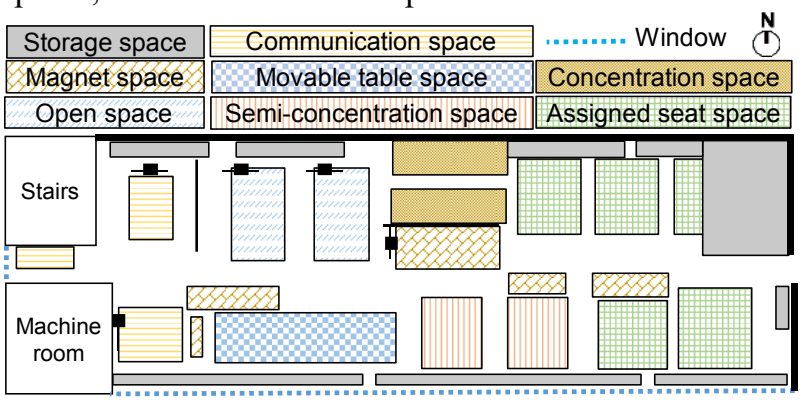

Fig. 1. Layout of the ABW office.

\subsection{Questionnaires}

Table 1 shows the details of each questionnaire. To ascertain the relationship between individual workers' attributes, three types of questionnaires were implemented in the entire building and $\mathrm{ABW}$ office.

Table 1. Details of each questionnaire.

\begin{tabular}{c|l|l|c}
\hline Questionnaire & Q1 (one time) & Q2 (one time) & Q3 (every day) \\
\hline Date & \multicolumn{2}{|c|}{ Oct/4 Oct/16/2017 } & $\begin{array}{c}\text { Oct/3 } \\
\text { Oct/20/2017 }\end{array}$ \\
\hline Target office & $\begin{array}{l}\text { Entire building } \\
(\mathrm{N}=203)\end{array}$ & \multicolumn{2}{|c}{$\begin{array}{c}\text { ABW office } \\
(\mathrm{N}=37)\end{array}$} \\
\hline Survey items & $\begin{array}{l}\text { 1. Personality } \\
\text { 2. Personal control } \\
\text { 3. Distraction }\end{array}$ & $\begin{array}{l}\text { 1. Satisfaction level } \\
\text { of indoor environment } \\
\text { 2. Factors of seat selection }\end{array}$ & $\begin{array}{l}\text { 1. Selected seat } \\
\text { 2. Work type and } \\
\text { concentration level }\end{array}$ \\
\hline \multicolumn{4}{c}{$\mathrm{N}:$ Number of subjects }
\end{tabular}

First, a survey (Q1) on personality traits, personal control, and distraction was conducted for the entire building from 4th to 16th October, 2017, to investigate the relationship between individual workers' attributes and the factors that distract them from their work. Personality traits were assessed using the Japanese Ten Item Personality Inventory (TIPI-J) [5]. The TIPI-J is a translation of the TIPI created by Gosling et al. [6], a measure of the Big Five personality traits of Extraversion, Agreeableness, Openness to experience, Neuroticism, and Conscientiousness. It comprises two questions (positive and negative sides) for each factor, answered on a seven-point Likert scale from 'Disagree strongly' to 'Agree strongly'. In addition, 8 questions were set to investigate personal control regarding the indoor environment and work-style (rated on a five-point Likert scale ranging from 'Strongly Disagree' to 'Strongly Agree'), and 27 questions were set to identify the possible causes of distraction (rated on a five-point Likert scale ranging from 'Least Distracted' to 'Most Distracted'), such as air quality and sanitation, sound, light, ICT (Information and Communication Technology), interior environment.

Additionally, during the same period, another survey (Q2) was conducted to the ABW office workers to investigate their satisfaction with the indoor environment (thermal, light, IAQ, sound, space, internet, and visual) and the factors that affect seat selection.
Subsequently, a questionnaire (Q3) was completed by employees every day after work, from 3rd to 20th October, 2017. It comprised items pertaining to the selected seat and the time spent at that seat, work type ('data entry or paper work', 'idea gathering', or 'others'), and concentration level achieved for each type of work (rated on a five-point Likert scale ranging from 'could not concentrate' to 'could concentrate well').

\section{Results}

The following data were analysed to ascertain the relationship between individual workers' attributes. For Q1, the response rate was $56.2 \%$, and data on 114 individuals (106 males, 8 females) were analysed. For Q2, the response rate was $62.2 \%$, and data on 23 individuals (22 males, 1 female) were analysed. For Q3, the response rate was $67.6 \%$, and data on 25 individuals (24 males, 1 female) were analysed. Spearman's correlation analyses were conducted using SPSS ver. 24.

\subsection{Workers' attributes and distraction}

\subsubsection{Personality traits/age and distraction}

Table 2 shows the relationship among personality traits/age and distraction during data entry or paper work. Some weak correlations were observed between personalities/age and environmental factors causing distraction. For example, workers displaying higher agreeableness tended to be more distracted by the ICT environment or interior environment. In addition, some negative correlations were observed among extraversion or openness to experience and environmental factors of distraction. There were no correlation between age and distraction.

Table 2. Relationship among personality traits/age and distraction during data entry or paper work.

\begin{tabular}{|c|c|c|c|c|c|}
\hline \multicolumn{2}{|c|}{ Environment } & Factors & Extraversion & Agreeableness & Openness to \\
\hline \multirow{9}{*}{ 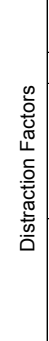 } & Sound & $\begin{array}{l}\text { sound from others } \\
\text { (footsteps, etc.) }\end{array}$ & $-.23 *$ & .03 & -.12 \\
\hline & Light & natural light & -.12 & .03 & -.28 ** \\
\hline & \multirow{3}{*}{ ICT } & $\begin{array}{l}\text { PC communication } \\
\text { environment }\end{array}$ & .01 & $.27^{\star *}$ & -.04 \\
\hline & & $\begin{array}{l}\text { number and capacity of } \\
\text { electrical outlets }\end{array}$ & .01 & $.29 * *$ & -.15 \\
\hline & & location of electrical outlets & -.02 & $.31^{* *}$ & -.14 \\
\hline & \multirow{4}{*}{ Interior } & crowdiness arround the seat & -.08 & .05 & $-.19 *$ \\
\hline & & openess of the front side & -.04 & $.21 *$ & -.10 \\
\hline & & non-height adjustable desks & -.12 & .02 & $-.19 *$ \\
\hline & & types or position of furnituire & -.01 & .08 & -.05 \\
\hline
\end{tabular}

Table 3 shows the relationship among personality traits/age and distraction during idea gathering. Several weak correlations were found between agreeableness, openness to experience, neuroticism, and distraction.

As observed for data entry or paper work, workers displaying higher agreeableness tended to be more distracted by the ICT environment when engaging in idea gathering. On the other hand, a positive correlation was observed between the light environment and ability to perform idea gathering. Regarding neuroticism, some 
correlations were observed with the ICT and interior environment, while there were no correlations in the case of data entry or paper work. Specifically, for idea gathering, workers displaying higher neuroticism tended to be more distracted by the location of electrical outlets, interior design, and atmosphere of the office.

Although no correlation was found between age and distraction during data entry, some correlation was seen for idea gathering. Specifically, older workers tended to be more distracted by the sound and light environment, and less distracted by the interior environment.

Table 3. Relationship among personality traits/age and distraction during idea gathering.

\begin{tabular}{|c|c|c|c|c|c|c|}
\hline \multicolumn{2}{|c|}{ Environment } & Factors & Agreeableness & Openness to & Neuroticism & Age \\
\hline \multirow{11}{*}{ 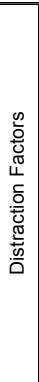 } & \multirow{2}{*}{ Sound } & noise of air-conditioner & .12 & -.16 & .15 & $.20^{*}$ \\
\hline & & outdoor noise & .13 & -.13 & .14 & $.21 *$ \\
\hline & \multirow{2}{*}{ Light } & brightness at the desk & .04 & -.13 & .06 & $.20 *$ \\
\hline & & brightness of the room & 22 * & -.13 & -.05 & .23 * \\
\hline & \multirow[b]{2}{*}{ ICT } & $\begin{array}{l}\text { number and capacity of } \\
\text { electrical outlets }\end{array}$ & $.21 *$ & -.08 & .14 & -.05 \\
\hline & & $\begin{array}{l}\text { location of electrical } \\
\text { outlets }\end{array}$ & $.29 * *$ & -.12 & $.21^{* *}$ & -.11 \\
\hline & \multirow{5}{*}{ Interior } & poor visibility & .22 * & -.08 & .17 & -.04 \\
\hline & & insufficient work space & .02 & -.09 & .01 & -.21 * \\
\hline & & close proximity to others & .09 & $-.25^{* *}$ & .00 & -.06 \\
\hline & & interior design & .12 & -.05 & $.26^{* *}$ & -.07 \\
\hline & & atmoshere/ambiance & .13 & -.02 & $.26^{* *}$ & -.09 \\
\hline
\end{tabular}

\subsubsection{Personal control and distraction}

Table 4 shows the relationship between personal control and distraction. Workers who could cope well with external stimuli tended not to be distracted by sound, ICT, interior environment, and so on. Additionally, it was suggested that workplace-related personal control, such as 'being able to work where they want' or 'being able to adjust the layout or furniture according to one's personal preferences' could help workers cope well with several distractions caused by environmental factors.

Table 4. Relationship between personal control and distraction.

\begin{tabular}{|c|c|c|c|c|c|c|c|}
\hline $\begin{array}{l}\text { work } \\
\text { type }\end{array}$ & \multicolumn{2}{|c|}{ Environment } & Factors & $\begin{array}{c}\text { Coping well } \\
\text { with external } \\
\text { stimuli such } \\
\text { as noise }\end{array}$ & $\begin{array}{c}\text { Working } \\
\text { where you } \\
\text { want }\end{array}$ & \begin{tabular}{|c|} 
Adjustability \\
of thermal \\
environment \\
for personal \\
preferences
\end{tabular} & $\begin{array}{c}\text { Adjustability } \\
\text { of layout or } \\
\text { furniture for } \\
\text { personal } \\
\text { prferences }\end{array}$ \\
\hline \multirow{13}{*}{ 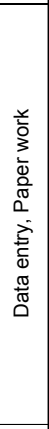 } & & \multirow{2}{*}{$\begin{array}{l}\text { Air quality and } \\
\text { sanitary }\end{array}$} & \multirow{2}{*}{$\begin{array}{l}\text { ambient temperature } \\
\text { air quality (cleanliness, } \\
\text { smell, etc.) }\end{array}$} & $-.25^{\star *}$ & .05 & $-.29^{\star \star}$ & \\
\hline & & & & $-.21 *$ & .00 & -.09 & -.03 \\
\hline & & \multirow{3}{*}{ Sound } & $\begin{array}{l}\text { sound from others } \\
\text { (footsteps, etc.) }\end{array}$ & -.23 * & -.02 & -.10 & .03 \\
\hline & & & conversation by others & $-.28^{* *}$ & .03 & -.14 & -.06 \\
\hline & & & outdoor noise & $-.22^{*}$ & .13 & -.05 & .12 \\
\hline & & Light & natural light & -.22 * & -.02 & -.08 & .02 \\
\hline & & \multirow{3}{*}{ ?. } & \multirow{3}{*}{$\begin{array}{l}\text { PC communication } \\
\text { environment } \\
\text { number and capacity of } \\
\text { electrical outlets } \\
\text { location of electrical } \\
\text { outlets }\end{array}$} & -.12 & -.15 & $-.25^{* *}$ & -.23 * \\
\hline & & & & $-.30^{* *}$ & -.14 & -.14 & .04 \\
\hline & & & & -.21 * & -.14 & -.09 & -.02 \\
\hline & & \multirow{4}{*}{ Interior } & visibility from others & $-.31^{\star \star}$ & -.11 & -.03 & -.08 \\
\hline & & & $\begin{array}{l}\text { crowdiness arround the } \\
\text { seat }\end{array}$ & $-.27^{* *}$ & -.21 * & $-.25^{* *}$ & -.29 ** \\
\hline & & & $\begin{array}{l}\text { non-height adjustable } \\
\text { chairs }\end{array}$ & $-.25^{* *}$ & .04 & -.07 & .02 \\
\hline & & & $\begin{array}{l}\text { non-height adjustable } \\
\text { desks }\end{array}$ & $-.21 *$ & -.09 & -.07 & .08 \\
\hline \multirow{5}{*}{ 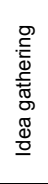 } & \multirow{5}{*}{ 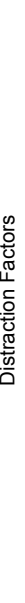 } & $\begin{array}{l}\text { Air quality and } \\
\text { sanitary }\end{array}$ & ambient temperature & -.17 & .03 & $-.37^{* *}$ & -.12 \\
\hline & & \multirow{2}{*}{ Sound } & $\begin{array}{l}\begin{array}{l}\text { sound from others } \\
\text { (footsteps, etc.) }\end{array} \\
\end{array}$ & $-.24^{* *}$ & -.02 & .06 & .00 \\
\hline & & & conversation by others & $-.25^{* *}$ & .02 & -.05 & -.08 \\
\hline & & \multirow{2}{*}{ Interior } & insufficient work space & -.03 & .11 & $-.21^{*}$ & .05 \\
\hline & & & $\begin{array}{l}\begin{array}{l}\text { types or position of } \\
\text { furnituire }\end{array} \\
\end{array}$ & -.10 & .09 & $-.19^{*}$ & .08 \\
\hline
\end{tabular}

Note. $\mathrm{n}$ (number of samples) $=114{ }^{* *} . p<0.01{ }^{*} . p<0.05$

Spearman's rank correlation coefficient

\subsection{Satisfaction level of the indoor environment and distraction}

An analysis of the relationship between the distraction level of workers and their satisfaction with the indoor environment revealed that workers with a higher degree of distraction tended to have lower levels of satisfaction with the indoor environment, regardless of the type of work. Particularly, the higher the distraction of ICT or interior environment, the lower the satisfaction level.

\subsection{Satisfaction level of the indoor environment and personal control}

Fig. 2 shows the relationship between personal control and satisfaction of the indoor environment. Workers who could cope well with external stimuli tended to have higher levels of satisfaction with the indoor environment. A similar tendency was observed among workers who worked where they wanted to.

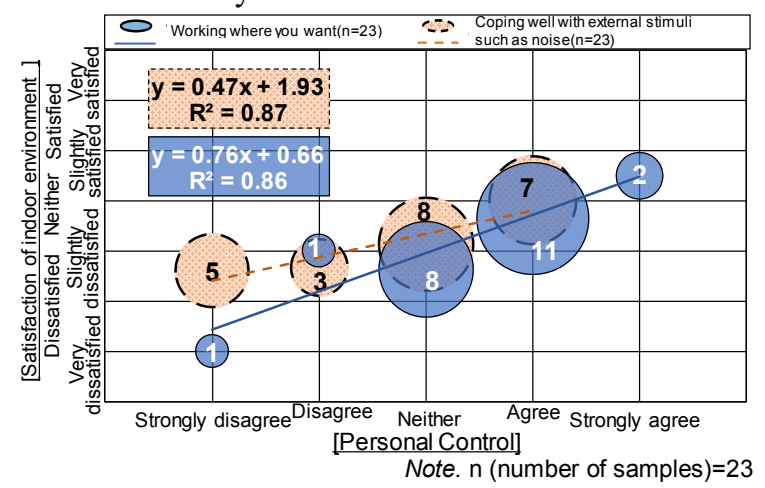

Fig. 2. Relationship between personal control and satisfaction of indoor environment.

\subsection{Workers' attributes and seating selection}

Fig. 3 shows the relationship between personality traits and the selection of seats at the beginning of work. Each personality score obtained from the questionnaire was analysed in relation to the selection of seats at the beginning of work. Seat selection differed based on personality scores. Specifically, workers displaying higher extraversion tended to choose open spaces more often as compared to concentration spaces. On the other hand, those displaying higher neuroticism or openness to experience tended to choose movable table space more often as compared to other types of seats.

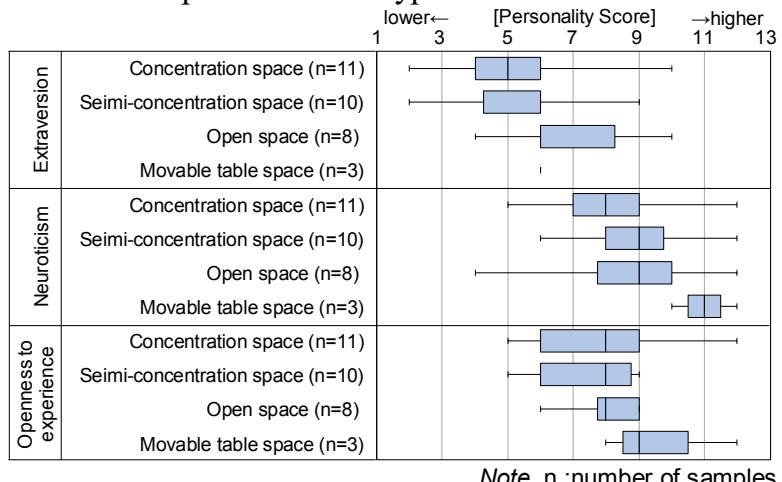

Fig. 3. Relationship between personality traits and selection of seat at the beginning of the work. 


\subsection{Seat selection tendency and concentration level}

Fig. 4 shows the occupancy rate for each type of seat by workers who did not have assigned seats. The numerical value in the figure indicates the total hours the worker occupied each seat type during the investigation period. While few workers changed seats during the same day, a certain number of workers changed their seats each day. Therefore, in order to confirm the influence of changing the seats on the level of concentration on work, workers were divided into the following two groups: 14 workers $(\mathrm{a}-\mathrm{n})$ that occupied the same type of seats for more than $90 \%$ of the time, and 11 workers (o - y) who exhibited more variation in their choice of seats.

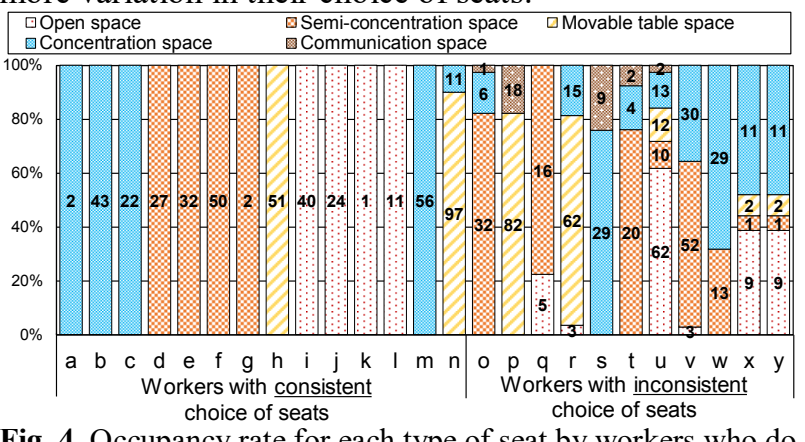

Fig. 4. Occupancy rate for each type of seat by workers who do not have assigned seats.

Figure 5 shows work type and degree of concentration. Regardless of the type of work, workers who changed their type of seat each day showed a higher percentage of concentration at work than did those who selected the same type of seat each day.

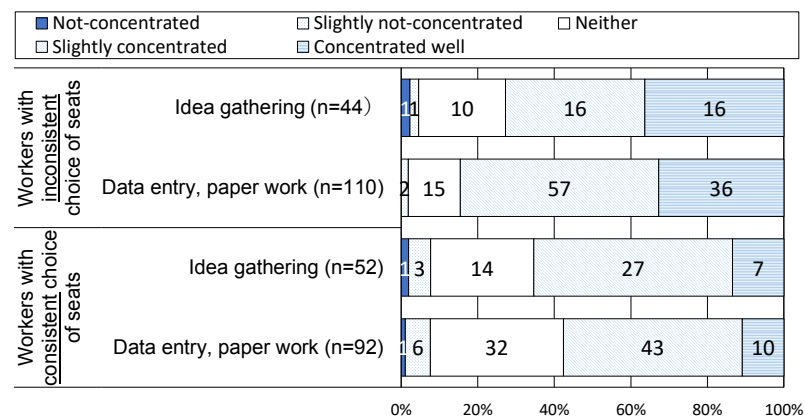

Fig. 5. Work type and degree of concentration.

\section{Discussion}

Three types of questionnaires were administered in the entire building and ABW office in the present study.

In relation to environmental factors of distraction, some correlations were observed among personality traits, age, and personal control. It was revealed that there are several tendencies among workers in the type of work environment needed to concentrate according to their individual attributes. Additionally, satisfaction with the indoor environment, which contributes to higher intellectual productivity [7], was correlated with distraction and personal control. Thus, workers' personal attributes may influence their intellectual productivity.

Furthermore, the field survey revealed that workers tended to select different workspaces depending on their personalities. While few workers in an ABW office changed seats during the same day, two patterns of daily seat selection were confirmed. Specifically, some changed their type of seat each day, while others selected the same type of seat each day. The former showed a higher percentage of concentration at work than the latter did, suggesting that changing seats daily may improve concentration at work, and thus increasing productivity.

\section{Conclusion}

As observed for research workers in the present study, even in the same job type, various attributes could be observed among workers. In the future, in order to design offices that facilitate higher productivity, it is necessary to design spaces considering individual workers' attributes rather than the attributes of general groups based on occupation. Particularly, it is necessary that a diverse environment is provided, where workers can select their workplace according to their preferences for sound, interior environment, and other environmental factors.

Additionally, the present study revealed that workers who changed their seat type each day may have been well adapted to $\mathrm{ABW}$, while those who selected the same type of seat each day may not have. It seems to be necessary to consider the workers' attributes in the introduction of $\mathrm{ABW}$ itself.

This study was supported by the Takenaka Research \& Development Institute. The authors would like to express sincere gratitude to all those involved in this study for their cooperation.

\section{References}

1. M. Takahashi et al. Effects of Active Design for Workplace on Occupants Behavior Part 2 Productivity (SHASE. 8, 25-28, 2017)

2. L. Engelen et al. Is activity-based working impacting health, work performance and perceptions? A systematic review (Build. Res. Inf. 47, 468-479, 2018)

3. C. Wohlers et al. Choosing where to work at worktowards a theoretical model of benefits and risks of activity-based flexible offices (Ergonomics 60 (4), 467-486, 2017)

4. A. Seddigh et al. Does personality have a different impact on self-rated distraction, job satisfaction, and job performance in different office types? (PLoS One 11 (5), 2016)

5. A. Oshio et al. Development, Reliability, and Validity of the Japanese Version of Ten Item Personality Inventorn (Jpn. J. Pers. 21 ,40-52, 2012)

6. S. D. Gosling et al. A very brief measure of the BigFive personality domains (J. Res. Pers. 37, 504-528, 2003)

7. T. Ikaga et al. The Influence of Office Building Space and Communication on Intellectual Productivity (AIJ 3, 149-152, 2010) 